PREPARED FOR THE U.S. DEPARTMENT OF ENERGY, UNDER CONTRACT DE-AC02-76CH03073

PPPL-3756

PPPL-3756

UC-70

Equilibria and Stability of JET Discharges with Zero Core Current Density

by

B.C. Stratton, N.C. Hawkes, G.T.A. Huysmans, J.A. Breslau, L.E. Zakharov, B. Alper, R.V. Budny, C.D. Challis, R. Deangelis, V. Drozdov, C. Fenzi,

C. Giroud, T.C. Hender, J. Hobirk, S.C. Jardin, E. Joffrin, P.J. Lomas, P. Lotte, J. Mailloux, W. Park, E. Rachlew,

S. Reyes-Cortes, E. Solano, T. Tala,

K-D. Zastrow, and JET-EFDA Contributors

October 2002
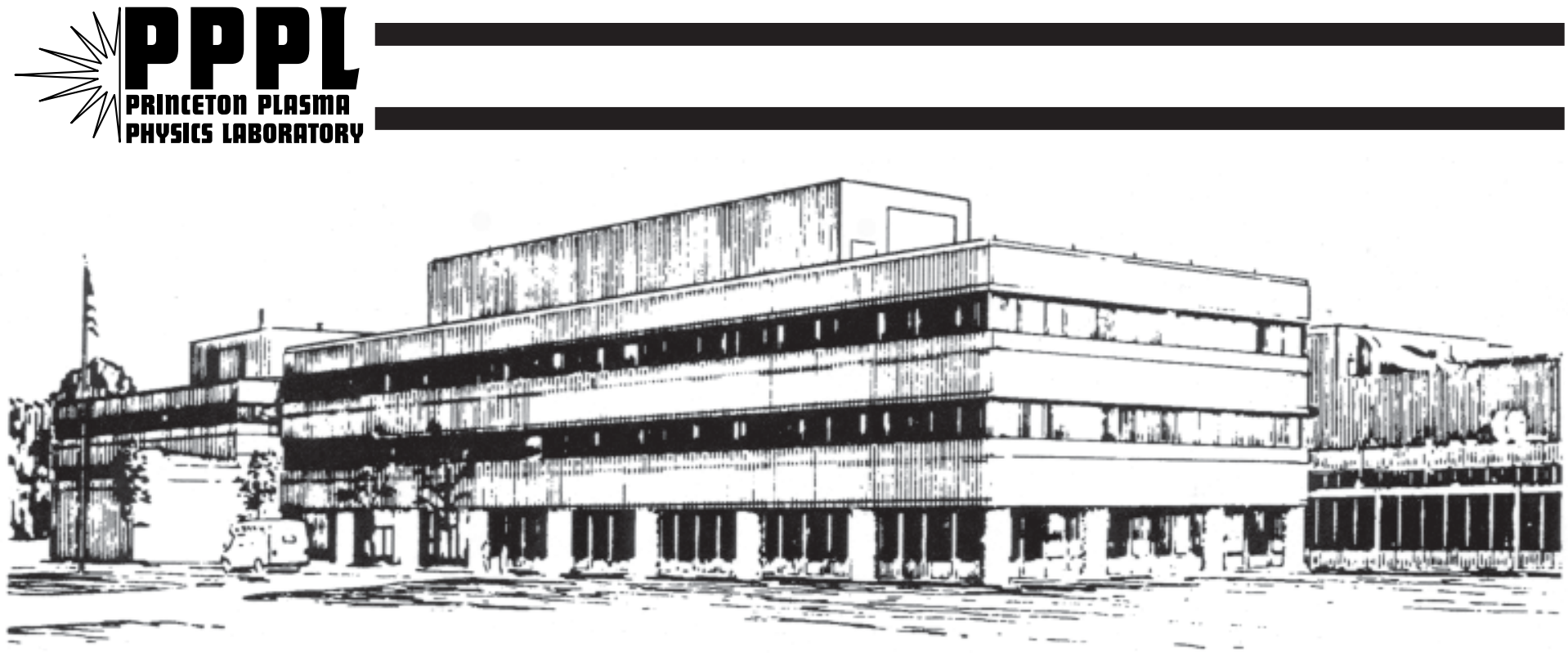

PRINCETON PLASMA PHYSICS LABORATORY PRINCETON UNIVERSITY, PRINCETON, NEW JERSEY 


\section{PPPL Reports Disclaimer}

This report was prepared as an account of work sponsored by an agency of the United States Government. Neither the United States Government nor any agency thereof, nor any of their employees, makes any warranty, express or implied, or assumes any legal liability or responsibility for the accuracy, completeness, or usefulness of any information, apparatus, product, or process disclosed, or represents that its use would not infringe privately owned rights. Reference herein to any specific commercial product, process, or service by trade name, trademark, manufacturer, or otherwise, does not necessarily constitute or imply its endorsement, recommendation, or favoring by the United States Government or any agency thereof. The views and opinions of authors expressed herein do not necessarily state or reflect those of the United States Government or any agency thereof.

\section{Availability}

This report is posted on the U.S. Department of Energy's Princeton Plasma Physics Laboratory Publications and Reports web site in Fiscal Year 2003. The home page for PPPL Reports and Publications is: http://www.pppl.gov/pub_report/

DOE and DOE Contractors can obtain copies of this report from:

U.S. Department of Energy

Office of Scientific and Technical Information

DOE Technical Information Services (DTIS)

P.O. Box 62

Oak Ridge, TN 37831

Telephone: (865) 576-8401

Fax: (865) 576-5728

Email: reports@adonis.osti.gov

This report is available to the general public from:

National Technical Information Service

U.S. Department of Commerce

5285 Port Royal Road

Springfield, VA 22161

Telephone: $1-800-553-6847$ or

(703) $605-6000$

Fax: (703) 321-8547

Internet: http://www.ntis.gov/ordering.htm 


\title{
EQUILIBRIA AND STABILITY OF JET DISCHARGES WITH ZERO CORE CURRENT DENSITY
}

\author{
B. C. STRATTON ${ }^{1}$, N. C. HAWKES ${ }^{2}$, G. T. A. HUYSMANS ${ }^{3}$, J. A. BRESLAU ${ }^{1}$, \\ L. E. ZAKHAROV ${ }^{1}$, B. ALPER ${ }^{2}$, R. V. BUDNY ${ }^{1}$, C. D. CHALLIS ${ }^{2}$, R. DEANGELIS ${ }^{4}$, \\ V. DROZDOV ${ }^{2}$, C. FENZI $^{3}$, C. GIROUD ${ }^{5}$, T. C. HENDER ${ }^{2}$, J. HOBIRK ${ }^{6}$, S. C. JARDIN ${ }^{1}$, \\ E. JOFFRIN ${ }^{3}$, P. J. LOMAS ${ }^{2}$, P. LOTTE ${ }^{3}$, J. MAILLOUX ${ }^{2}$, W. PARK ${ }^{1}$, E. RACHLEW ${ }^{7}$, \\ S. REYES-CORTES ${ }^{8}$, E. SOLANO ${ }^{9}$, T. TALA ${ }^{10}$, K-D. ZASTROW $^{2}$, AND \\ JET-EFDA CONTRIBUTORS*
}

${ }^{1}$ Princeton Plasma Physics Laboratory, PO Box 451, Princeton, NJ, 08543, USA

${ }^{2}$ Euratom/UKAEA Fusion Association, Culham Science Centre, Abingdon, OX14 3DB, UK

${ }^{3}$ Association Euratom-CEA, Cadarache, F13108, France

${ }^{4}$ Association Euratom-ENEA sulla Fusione, CRE Frascati, Roma, Italy

${ }^{5}$ FOM-Institut voor Plasmafysica "Rijnhuizen", Associatie EURATOM-FOM, Trilateral Euregio Cluster, P. O. Box 1207, 3430 BE Niewgen, The Netherlands

${ }^{6}$ Max-Planck-Institut für Plasmaphysik, Euratom Association, 85740, Garching, Germany

${ }^{7}$ KTH-Physics, SCFAB, VR Association, 10691, Stockholm, Sweden

${ }^{8}$ Euratom/IST Association, Centro de Fusao Nuclear, 1049-001, Lisboa, Portugal

${ }^{9}$ Association EURATOM-CIEMAT para Fusion, CIEMAT, Spain and EFDA CSU JET, Abingdon, OX14 3EA, UK

${ }^{10}$ Association Euratom-TEKES, VTT Chemical Technology, Espoo, P. O. Box 1404, Finland

*See Annex 1 in J. Paméla , OV/1-4 (IAEA Fusion Energy Conference 2002)

e-mail address of main author: bstratton@pppl.gov

\begin{abstract}
Injection of Lower Hybrid Heating and Current Drive (LHCD) into the current ramp-up phase of JET discharges can produce extremely reversed q-profiles characterized by a core region of near zero current density (within Motional Stark Effect diagnostic measurement errors). Non-inductive, off-axis co-current drive induces a back electromotive force inside the non-inductive current radius that drives a negative current in the plasma core. The core current density does not go negative, although current diffusion calculations indicate that there is sufficient LHCD to cause this. The clamping of the core current density near zero is consistent with $n=0$ reconnection events redistributing the core current soon after it goes negative. This is seen in reduced MHD simulations and in nonlinear resistive MHD simulations which predict that these discharges undergo $\mathrm{n}=0$ reconnection events that clamp the core current near zero.
\end{abstract}

\section{INTRODUCTION}

Injection of Lower Hybrid Heating and Current Drive (LHCD) into the current ramp-up phase of JET discharges can produce extremely reversed q-profiles characterized by a core region of very small or zero current density (within Motional Stark Effect diagnostic measurement errors) and $\mathrm{q}_{\min }>1$ [1]. This phenomenon is termed the "current hole". It occurs because non-inductive, off-axis current drive in the same direction as the Ohmic current induces a back electromotive force inside the non-inductive current drive radius that decreases the core current density. $\mathrm{T}_{\mathrm{e}}$-profiles show the presence of an internal transport barrier (ITB) during the LHCD prelude phase. These discharges can exhibit strong ITBs and transient high performance during a subsequent high-power heating phase [2]. If the non-inductive current drive is strong enough relative to the Ohmic current, the total current could in principal be driven negative in the core. This does not happen [3], although current diffusion calculations indicate that there is sufficient LHCD to cause this. The clamping of the core current density near zero is shown to be consistent with $\mathrm{n}=0$ MHD events redistributing the core current soon after it goes negative [4, 5]. Current hole discharges are also observed on JT-60U, where the off-axis current drive is due to the 

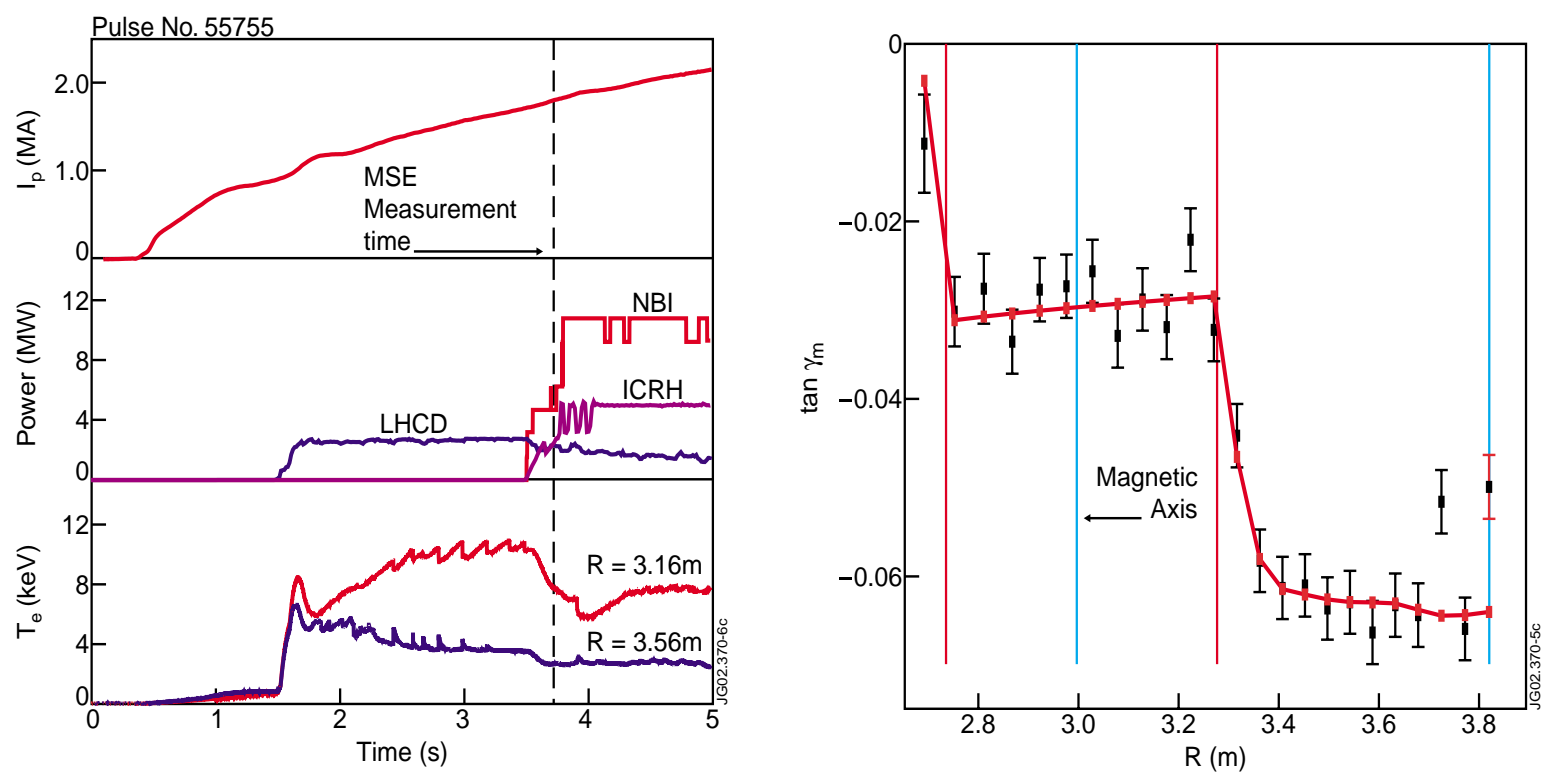

FIG. 1. Current hole discharge parameters.

FIG. 2. MSE pitch angle profile (points) and ESC reconstruction best fit (solid line).

bootstrap current generated by neutral beam injection [6]. This paper summarizes work on JET current hole discharges with an emphasis on recent results.

\section{EXPERIMENTAL SCENARIO}

The time evolution of the early part of a JET current hole discharge with $\mathrm{B}_{\phi}=3.45 \mathrm{~T}$ is shown in Fig. 1 . The LHCD prelude starts at $1.5 \mathrm{~s}$. It is followed by a short pre-heat phase of low-power neutral beam and ICRH injection and then a longer high-power main heating phase. The $T_{e}$ time evolution shows 'high-q' sawteeth [7] that are always seen during the LHCD prelude in JET discharges with extreme shear reversal. The pitch angle profile measured by the MSE diagnostic $\left(\tan \gamma_{\mathrm{m}}\right)$ at $3.78 \mathrm{~s}$ is shown as the points in Fig. 2. For this case of only the beam viewed by the MSE diagnostic injected at the measurement time, $\gamma_{m}$ is proportional to the magnetic field pitch angle, $\gamma=\tan ^{-1}\left(B_{Z} / B_{\phi}\right)$, with an offset due to the non-zero neutral beam injection angle with respect to the midplane. Thus, the flat region in $\tan \gamma_{\mathrm{m}}$ shown in Fig. 2 indicates a large region of nearly zero $\mathrm{B}_{\mathrm{Z}}$, or very small core current density according to Ampère's Law [3]. This is the characteristic feature of current hole discharges and it can persist for several seconds if the LHCD remains on. The effect of the radial component of the plasma electric field, $E_{r}$, on the MSE measurement is negligible at this time [3]. Measurements at the earliest time at which the beam viewed by the MSE diagnostic can be injected show that the current hole is well established by $0.75 \mathrm{~s}$ into the LHCD pulse [5].

\section{EQUILIBRIUM RECONSTRUCTION OF CURRENT HOLE PLASMAS}

Although accurate equilibrium reconstruction of current hole discharges is challenging because the poloidal flux, $\psi$, inside the hole region is nearly zero, reliable reconstructions have been obtained using a modified version of the EFIT code [3] and the ESC code [5, 8]. The resulting current density profiles show a strong gradient at the edge of the current hole with a narrow peak just outside it. The small current density inside the current hole is consistent with a measurement made by rapidly moving the plasma in the radial direction so that a given point in the plasma was swept across adjacent spatial channels of the MSE diagnostic [3], eliminating the effect of systematic uncertainties in the diagnostic 

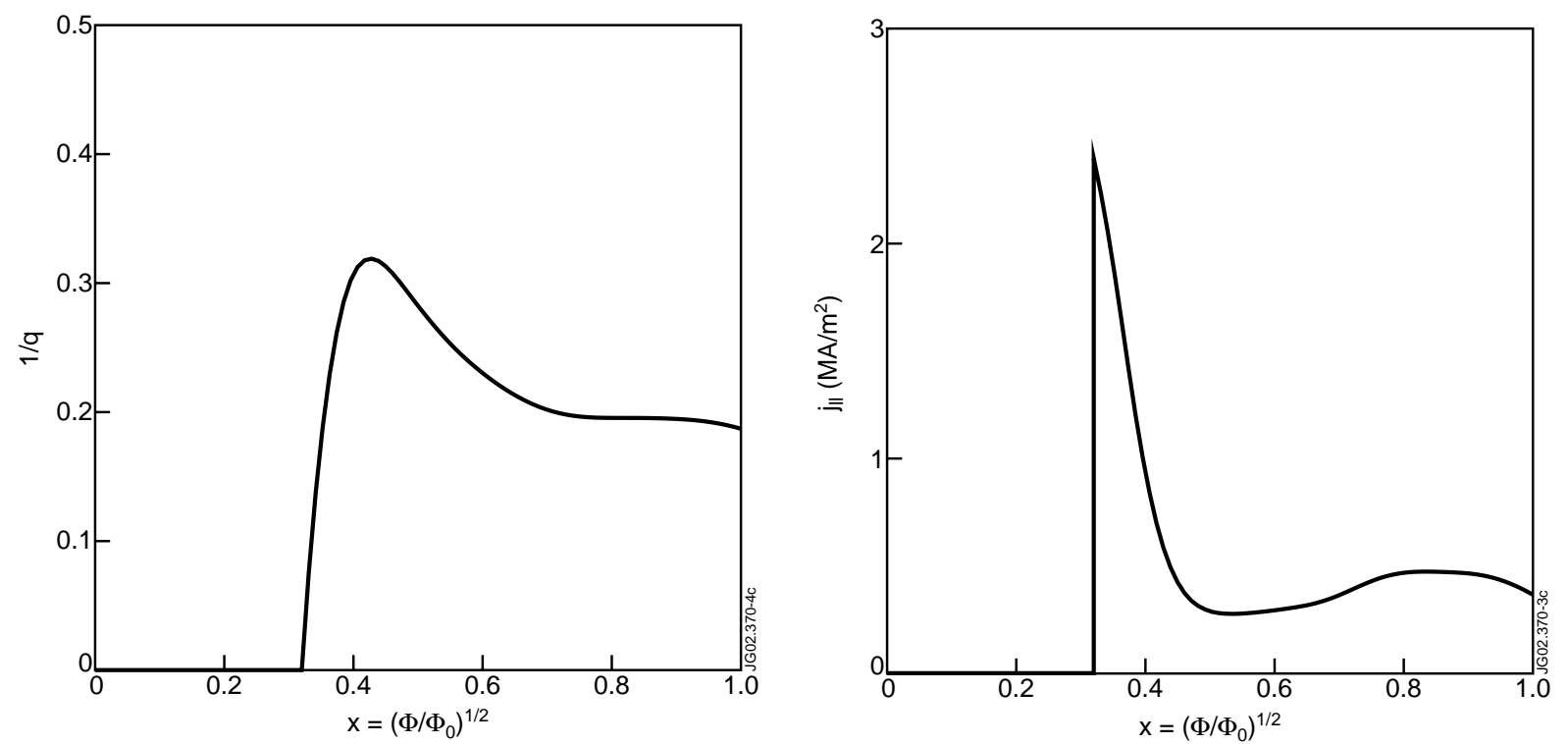

FIG. $3 \mathfrak{t}=1 / q$ profile (left) and $j_{\|}$profile (right) from ESC reconstruction of current hole discharge shown in figures 1 and 2.

calibration. Assuming constant current density inside the current hole, this measurement yields a small core current density of $0.08 \pm 0.025 \mathrm{MA} / \mathrm{m}^{2}$ compared to the off-axis peak value of $\sim 1 \mathrm{MA} / \mathrm{m}^{2}$.

The ESC code uses a free-boundary solver constrained by the measured coil currents and magnetics data to determine the plasma boundary; a fixed boundary solver constrained by the MSE pitch angle measurements then determines the magnetic geometry and the current density profile [5]. The flux surfaces are labeled by the variable $\mathrm{x}=\left(\Phi / \Phi_{0}\right)^{1 / 2}$, where $\Phi$ is the toroidal flux and $\Phi_{0}$ is the total value through the plasma cross section. A standard ESC reconstruction of a current hole discharge with small finite core current is shown in ref. 5. Recently, ESC has been modified to include a current hole model in which the current density is identically zero and the pressure profile is flat over a specified region in the plasma core. (The observed pressure profile is often flat inside the current hole within temperature and density profile measurement errors [3].) This model is a good approximation because little (1\% or less) of the total current flows in the hole region. It has been used to reliably reconstruct a number of current hole discharges. The solid red line in Fig. 2 shows that such a reconstruction with the radius of the current hole set to $x=0.33$ (indicated by the vertical red lines in Fig. 2) reproduces the MSE pitch angle measurements within the error bars. (The small positive slope in the calculated tan $\gamma_{\mathrm{m}}$ inside the current hole is due to the change in the neutral beam injection angle with respect to the midplane across the diagnostic field of view.) Profiles of the rotational transform, $\mathfrak{l} \equiv \partial \psi / \partial \Phi=1 / \mathrm{q}$, and parallel current density, $\mathrm{j}_{\|}$, are shown in Fig. 3. The narrow peak in $\mathrm{j}_{\|}$at the edge of the current hole region arises from the sharp change in $\tan \gamma_{\mathrm{m}}$ at the edge of the flat region seen in Fig. 2.

\section{SIMULATION OF CURRENT HOLE EVOLUTION}

Theory shows that tokamak equilibria with a core region of zero current density and $\nabla \mathrm{p}=0$ can exist, but that no equilibria exist if the core current density is negative or $\nabla p \neq 0$ [9]. Two MHD simulations of current hole discharges offer an explanation for the observed clamping of the core current density near zero: 1) reduced non-linear MHD simulations, initially in cylindrical geometry [4] and recently including toroidal effects [10], show that a plasma with negative core current is unstable to $n=0$ resistive internal kink instabilities which lead to redistribution of the core current to prevent it from becoming negative; 


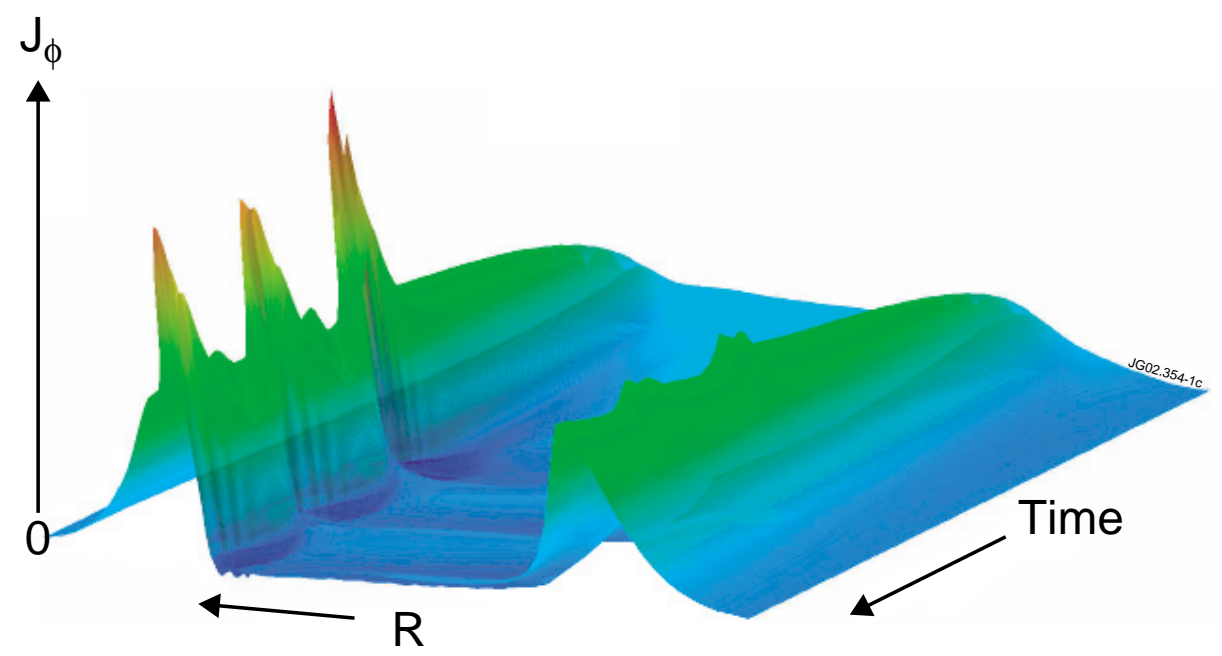

FIG. 4. 2-D Nonlinear resistive MHD simulation of current density in midplane showing repetitive clamping of core current density near zero.

and 2) full 2-D and 3-D nonlinear resistive MHD simulations in toroidal geometry with both a circular plasma cross-section and the experimental shape predict that these discharges undergo $n=0$ reconnection events (axisymmetric sawteeth) which clamp the core current near zero when $\mathfrak{l}=0$ at some point in the plasma [5].

Nonlinear resistive MHD simulations of the initial formation of the current hole and several axisymmetric sawtooth periods afterwards have been performed using the M3D code [5, 11]. Fig. 4 shows the predicted time evolution of the current density profile in the midplane from a 2-D simulation. The core current density falls initially and then clamps near zero due to an axisymmetric sawtooth that occurs when the core current density becomes sufficiently negative that an $\mathfrak{l}=\mathrm{n} / \mathrm{m}=0$ surface enters the plasma. The sharp peaks in the current density at the edges of the hole are due to the current sheet associated with the reconnection process. After the initial reconnection is complete, the process repeats several times if the LHCD remains on. The clamping of the core current density due to axisymmetric sawteeth is also seen in recent 3-D M3D code nonlinear resistive MHD simulations. The reconnection event is primarily $m=1$ but with a significant $m=2$ component in simulations done with the experimental plasma cross-section. The essential features of the reconnection process are most easily seen in a simulation done with a circular cross section. Fig. 5 shows the evolution of $\psi(\mathrm{R}, \mathrm{Z})$ during an axisymmetric sawtooth period; the magnetic island structure is similar to that of conventional $(n=1)$ sawteeth [5]. However, the axisymmetric sawteeth have the same symmetry as the equilibrium and should therefore be viewed as being due to a transient loss of conditions required for a normal equilibrium with nested flux surfaces [5].

Scaling of 2-D nonlinear resistive MHD simulations done at values of the Lundquist number in the range $1 \times 10^{3}$ to $2 \times 10^{4}$ to experimental values of $\sim 1 \times 10^{8}$ yields an estimated axisymmetric sawtooth period of $\sim 0.01 \mathrm{~s}$, similar to the period of several milliseconds predicted by the reduced MHD simulations [4]. These events have not yet been observed in the MSE $\gamma_{m}$ measurements. This is consistent with the prediction that the periodic changes in the core current density that follow the initial core current clamping near zero are small. Observation of the axisymmetric sawteeth using other diagnostic techniques is difficult because their $n=0$ character implies that their frequency independent of the toroidal flow speed. The axisymmetric sawteeth are distinct from the high-q sawteeth shown on the $\mathrm{T}_{\mathrm{e}}$ traces in Fig. 1, which are believed to be $n=1$ double-tearing modes [7]. 

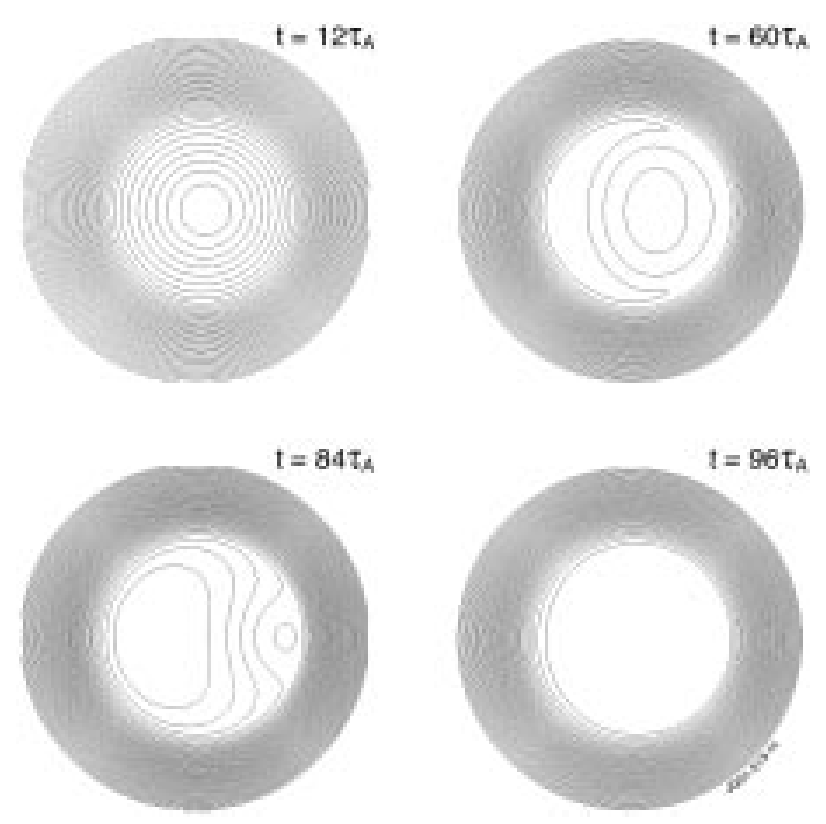

FIG. 5. Poloidal flux map, $\psi(R, Z)$, at four times in axisymmetric sawtooth period from M3D simulation with circular plasma cross section.

\section{CONCLUSIONS}

Significant progress has been made in the experimental characterization and theory of current hole plasmas. The challenge now is to experimentally determine if the predicted axisymmetric sawteeth are responsible for the observed core current clamping. Understanding the physics of the current hole is important not only for interpretation of present experiments but also to enable accurate predictions of current profile evolution in future devices with strong non-inductive current drive. If clamping of the core current density near zero can be relied on to prevent the core current from going negative during the non-inductive current build-up phase, it may be possible to raise the current much more rapidly than presently believed [12].

\section{ACKOWLEDGMENTS}

This work was conducted under the European Fusion Development Agreement and partly funded by Euratom, the UK Department of Trade and Industry, and the US Department of Energy (contract no. DE-AC02-76-CH03073).

\section{REFERENCES}

1. Hawkes, N. C., et al., Phys. Rev. Lett. 87 (2001) 115001-1.

2. Challis, C. D., et al., Plasma Phys. Control. Fusion 44 (2002) 1031.

3. Hawkes, N. C., et al., Plasma Phys. Control. Fusion 44 (2002) 1105.

4. Huysmans, G. T. A., et al., Phys. Rev. Lett. 87 (2001) 245002-1.

5. Stratton, B. C., et al., Plasma Phys. Control. Fusion 44 (2002) 1127.

6. Fujita, T., et al., Phys. Rev. Lett. 87 (2001) 245001-1.

7. Hender, T. C., et al., Plasma Phys. Control. Fusion 44 (2002) 1143.

8. Zakharov, L. E., and Pletzer, A. Phys. Plasmas 6 (1999) 4693.

9. Chu, M., and Parks, P. B., 'On Tokamak Equilibria with Zero Current or Negative Central Current Region' to appear in Phys. Plasmas (2002).

10. Huysmans, G. T. A., et al., 'MHD Stability of 'Current Hole' Plasmas', Joint Varenna-Laussane Workshop on the Theory of Fusion Plasmas (2002).

11. Park, W., Phys. Plasmas 6 (1999) 1796.

12. Jardin, S. C., Nucl. Fus. 40 (2000) 1101. 


\section{External Distribution}

Plasma Research Laboratory, Australian National University, Australia

Professor I.R. Jones, Flinders University, Australia

Professor João Canalle, Instituto de Fisica DEQ/IF - UERJ, Brazil

Mr. Gerson O. Ludwig, Instituto Nacional de Pesquisas, Brazil

Dr. P.H. Sakanaka, Instituto Fisica, Brazil

The Librarian, Culham Laboratory, England

Library, R61, Rutherford Appleton Laboratory, England

Mrs. S.A. Hutchinson, JET Library, England

Professor M.N. Bussac, Ecole Polytechnique, France

Librarian, Max-Planck-Institut für Plasmaphysik, Germany

Jolan Moldvai, Reports Library, MTA KFKI-ATKI, Hungary

Dr. P. Kaw, Institute for Plasma Research, India

Ms. P.J. Pathak, Librarian, Insitute for Plasma Research, India

Ms. Clelia De Palo, Associazione EURATOM-ENEA, Italy

Dr. G. Grosso, Instituto di Fisica del Plasma, Italy

Librarian, Naka Fusion Research Establishment, JAERI, Japan

Library, Plasma Physics Laboratory, Kyoto University, Japan

Research Information Center, National Institute for Fusion Science, Japan

Dr. O. Mitarai, Kyushu Tokai University, Japan

Library, Academia Sinica, Institute of Plasma Physics, People's Republic of China

Shih-Tung Tsai, Institute of Physics, Chinese Academy of Sciences, People's Republic of China

Dr. S. Mirnov, TRINITI, Troitsk, Russian Federation, Russia

Dr. V.S. Strelkov, Kurchatov Institute, Russian Federation, Russia

Professor Peter Lukac, Katedra Fyziky Plazmy MFF UK, Mlynska dolina F-2, Komenskeho Univerzita, SK-842 15 Bratislava, Slovakia

Dr. G.S. Lee, Korea Basic Science Institute, South Korea

Mr. Dennis Bruggink, Fusion Library, University of Wisconsin, USA

Institute for Plasma Research, University of Maryland, USA

Librarian, Fusion Energy Division, Oak Ridge National Laboratory, USA

Librarian, Institute of Fusion Studies, University of Texas, USA

Librarian, Magnetic Fusion Program, Lawrence Livermore National Laboratory, USA

Library, General Atomics, USA

Plasma Physics Group, Fusion Energy Research Program, University of California at San Diego, USA

Plasma Physics Library, Columbia University, USA

Alkesh Punjabi, Center for Fusion Research and Training, Hampton University, USA

Dr. W.M. Stacey, Fusion Research Center, Georgia Institute of Technology, USA

Dr. John Willis, U.S. Department of Energy, Office of Fusion Energy Sciences, USA

Mr. Paul H. Wright, Indianapolis, Indiana, USA 
The Princeton Plasma Physics Laboratory is operated by Princeton University under contract with the U.S. Department of Energy.

\author{
Information Services \\ Princeton Plasma Physics Laboratory \\ P.O. Box 451 \\ Princeton, NJ 08543
}

Phone: 609-243-2750

Fax: 609-243-2751

e-mail: pppl_info@pppl.gov

Internet Address: http://www.pppl.gov 